\title{
Response to Edmeades and McBride critique
}

\author{
J.D. MORTON ${ }^{1}$, A.D. STAFFORD ${ }^{2}$ and M.A. HAWKE 3 \\ ${ }^{1}$ Ballance Agri-Nutrients, PB 2290, Hastings \\ ${ }^{2}$ Ballance Agri-Nutrients, $P B$ 12503, Tauranga \\ ${ }^{3} \mathrm{MFH}$ Consultancy, $R D$ 4, Rotorua \\ Jeff.Morton@ballance.co.nz
}

This will be considered under the topic headings that were submitted.

\section{Introduction}

The conclusions in the original paper (Morton et al. 2014) did not include the first and second statements that Dr Edmeades cites. The statements were made in the body of the text as part of the discussion.

Dr Edmeades only partly quotes our second conclusion in that he fails to include "at the start of each pasture growth season" at the end of "Even very high rates of 300-600 kg K/ha/yr failed to elevate the soil QT K levels into the target range for near-maximum pasture production of 7-10".

We could not include the autumn soil test results in our statistical analysis because they were taken on a treatment and not a plot basis. There were two sentences in the Results section on the autumn soil test results and they were part of the Discussion. The length restriction on a conference paper meant that we had to prioritise the results that were included.

We concede that we should have expanded the statement that " $95 \%$ of maximum yield occurs at a QT K of 3" with "provided that adequate K fertiliser is applied at an economically optimal rate during the growth season".

Defining the soil QTK Pasture Production Function In the Edmeades et al. (2010) review paper it is stated that end of year soil $\mathrm{K}$ values were used as they reflected use of fertiliser $\mathrm{K}$ and hence pasture production responses during the previous 12 months. Dr Edmeades was consulted with regarding experimental design for the trials reported in Morton et al. (2014). Within this, we decided that the main individual plot soil sampling was carried out before the first $\mathrm{K}$ fertiliser treatment was applied in September. Therefore end-of-year soil testing must reflect the end of the full 12 month growth period before treatments start to be re-applied for the next year, in this case September. The autumn soil tests were carried out 6-8 months after the $\mathrm{K}$ treatments were first applied, not 12 months, so did not follow the convention.

We do not see how Dr Edmeades can suggest that the autumn soil QT K levels measured in these trials are consistent with the optimal range of $7-10$ when this optimal range was derived from soil QT K levels measured in the spring in the other trials on which this range was based.

For a mobile nutrient such as $\mathrm{K}$ on these high K-loss soils, soil testing in autumn after all the fertiliser $\mathrm{K}$ has been applied and the soil QT K levels are at their maximum could be misleading and result in insufficient $\mathrm{K}$ fertiliser being applied in future years. Fertiliser K requirements on high $\mathrm{K}$-loss soils are better assessed from the soil $\mathrm{K}$ status at the start of the growth season when soil QT K levels are at a minimum after winter leaching.

In response to the contention that time of soil sampling will influence the pasture production response to K, we offer the following simple statement. If on high K-loss soils, sampling is carried out before fertiliser is applied at the start of spring then a low soil QT K level will result in a large pasture production response to fertiliser $\mathrm{K}$ as long as there is no other source of $\mathrm{K}$ available in the soil. This is what occurred in our reported trials.

Research practice in most nutrient response trials carried out in New Zealand was to soil sample at the start of the growth season before fertiliser treatments were applied and to relate those levels to the pasture production response. So to be able to relate our results to the main body of earlier research, we needed to use September soil test results. Hence the individual plot soil testing was carried at that time.

\section{Measuring the true Soil K Status}

A large proportion of farmers sample in late winter/early spring when consistently higher soil moisture helps to minimise variability in the soil QT K test between years. As stated earlier, for these high K-loss soils there is the advantage that this is when soil QT K levels are at their lowest point so that there is a more accurate indication of how much $\mathrm{K}$ fertiliser is required. We contest that the convention "end of year" means the end of the growth season. Rather we contend that it means the end of the full year growth cycle before treatments are re-applied i.e. spring the following season before application.

Figures 5 and 6 in Edmeades and McBride's critique indicate that as the rate of fertiliser $\mathrm{K}$ increases above $150 \mathrm{~kg} \mathrm{~K} / \mathrm{ha} / \mathrm{yr}$, soil QT K levels at $0-75 \mathrm{~mm}, 75-150$ $\mathrm{mm}$ and $150-300 \mathrm{~mm}$ increase which is not surprising. We do not see how this alters our interpretation of the 
trial data - it supports our view that high $\mathrm{K}$ leaching is evident on these soils, making capital $\mathrm{K}$ approaches to maintaining high soil $\mathrm{K}$ fertility impractical. In the Edmeades et al. (2010) K review paper, the significance of $\mathrm{K}$ at depth occurs where soil QT K levels are low in the top $75 \mathrm{~mm}$ and plants may be able to extract $\mathrm{K}$ from lower depths and not respond to fertiliser K. In these trials, soil QT K levels are highest in the top $75 \mathrm{~mm}$ and decrease with depth.

\section{Managing soil K requirements}

Dr Edmeades emphasis on a critical clover K content of $2.0-2.5 \%$ contradicts his statement in the Edmeades et al. (2010) review paper that "There also seems to be good agreement that the critical concentration of $\mathrm{K}$ in legumes (white clover, subterranean clover and lucerne) for maximum production is in the range 1.5-2.0\%".

Our trial data at the Mamaku site shows that at the application rate of $150 \mathrm{~kg} \mathrm{~K} / \mathrm{ha} / \mathrm{yr}$, at 25 sampling points over the 3 years, clover $\mathrm{K}$ levels were less than $2 \%$ on just 4 occasions, and no samples had less than $1.5 \% \mathrm{~K}$.

At Pouakani, over 16 clover-only measurements, at $150 \mathrm{~kg} \mathrm{~K} /$ ha applied, mean clover $\% \mathrm{~K}$ was $1.9 \%$. While only on four occasions was K content greater than $2 \%$, it was greater than $1.5 \%$ on 15 of these 16 sampling points. At $300 \mathrm{~kg} \mathrm{~K} / \mathrm{ha}$ applied, the mean clover \%K was $2.9 \%$ over the 16 measurements, ranging between $2.08 \%$ and $3.4 \%$. This indicates that $300 \mathrm{~kg} \mathrm{~K} / \mathrm{ha}$ was excessively high while $150 \mathrm{~kg} \mathrm{~K} / \mathrm{ha}$ was marginally low at this site. Hence, the optimal rate according to clover $\mathrm{K}$ content lies somewhere between the 150 and $300 \mathrm{~kg} \mathrm{~K} / \mathrm{ha}$ rates at this site. However, a further consideration is that these rates of $\mathrm{K}$ were split over three applications, with the final application being made in February each year. It is likely that reducing the number of applications so that all of the $\mathrm{K}$ is applied in the spring-early summer growth period (Sept-Dec) will more efficiently increase clover $\% \mathrm{~K}$ concentrations over the critical spring-early summer clover growth period, giving the best economic return at lower $\mathrm{K}$ application rates. This is supported by clover $\% \mathrm{~K}$ data comparing $300 \mathrm{~kg} \mathrm{~K} /$ ha split over three applications vs the same rate of $\mathrm{K}$ applied in a single spring application.

Dr Edmeades states “.... soil QTK levels (0-75mm) measured in spring must be treated with caution. Under these circumstances autumn soil test results appear to be a more reliable measure of the soil K status..." and then "Based on the autumn soil QTK, it is apparent that soil QTK levels can be increased with sufficiently high $\mathrm{K}$ inputs to the optimal range of $7-10$, for near maximum pasture production."

We don't disagree that autumn soil QT K levels were greatly increased by the fertiliser inputs in spring. They would be, as there is little drainage over the drier summer period, and hence little $\mathrm{K}$ leaching. However,
Dr Edmeades is missing the point in regard to the autumn soil sampling for forward fertiliser planning, which is different to using it to explain historic yields. Farmers and consultants use soil tests to plan ahead in regard to fertiliser management, not explain what production has occurred in the past. If an autumn soil sampling approach was to be undertaken, the high soil QT K levels at that point would suggest that soil QT K levels are at or above the target "optimum" level. In this sense, the temptation would be to reduce or withhold fertiliser $\mathrm{K}$ inputs, without compromising production. However, as clearly shown by the spring soil tests, this would not be an appropriate strategy. Hence, while QT K in the autumn may reflect what has occurred in the $6-8$ months since the previous capital $\mathrm{K}$ inputs, it is likely to have little relevance to future fertiliser planning. Part of the reason this trial was undertaken was to demonstrate this point - that high $\mathrm{K}$ leaching on these soils makes a traditional "capital-K" followed by "maintenance-K" fertiliser management approach impractical. The spring soil QT K data shows that the high autumn QT K levels achieved from a capital K approach were not maintained over the winter leaching period. Hence, "capital" fertiliser K inputs would need to be annually repeated to lift soil QT K into the desired range. This was tested in a fourth year of data, when a uniform rate of $130 \mathrm{~kg} \mathrm{~K} / \mathrm{ha}$ was applied to all plots. At the autumn soil sampling at the end of the fourth year, the plots that had previously received $600 \mathrm{~kg} \mathrm{~K} / \mathrm{ha} / \mathrm{yr}$ for 3 years (i.e. $1800 \mathrm{~kg} \mathrm{~K} / \mathrm{ha}$ ) had a QT K $(0-75 \mathrm{~mm})$ of just 6.5 at both sites (in previous autumns these had ranged between 9 and 20).

We would contend a more rational approach to $\mathrm{K}$ fertiliser management on these high $\mathrm{K}$ loss soils is therefore:

a) Assess soil QT K in late winter/spring to gauge fertiliser requirements for the following production season. Sampling at this time makes it possible to more to accurately gauge true soil $\mathrm{K}$ fertility postwinter leaching (which can be variable depending on rainfall /drainage intensity) relevant to the season ahead.

b) Apply $\mathrm{K}$ fertiliser at sufficient rate $(120-150 \mathrm{~kg} \mathrm{~K} /$ ha on these high $\mathrm{K}$ loss soils, split over 2-3 dressings from spring to ensure sufficient $\mathrm{K}$ is available to the clover at all times during the spring - autumn. Monitor K sufficiency $(>2.0 \% \mathrm{~K})$ over the growing season using clover-only plant tissue testing

d) Reappraise fertiliser management based on these results

\section{Conclusions}

Dr Edmeades' criticism rests on one main point, which was answered in the question session after the paper was presented. 
This point is our use of soil QT K levels measured before fertiliser K was applied in the spring rather than the autumn-sampled levels. Publication of scientific results requires a comparison with previous data and most of the previous results used in the relevant database were based on spring soil test levels taken before fertiliser $\mathrm{K}$ was applied, 12 months after the application of previous fertiliser as per the trial convention. This timing of sampling was also chosen so that there would be no effect of freshly-applied $\mathrm{K}$ on the soil test level. The data in our paper clearly shows the futility of spending large amounts on annual fertiliser $\mathrm{K}$ applications when the resulting soil QT K levels of 7-10 are not sustained from year to year on high K-loss soils such as these. This is demonstrated in Dr Edmeades' Figures 1 and 2. Rather the trial results support the more feasible current policy of split applications of a lower more economic rate of $\mathrm{K}$ fertiliser. Economic analysis using the Overseer econometric model which uses all the $\mathrm{K}$ response data from trials on pumice soils predicts an economically optimal rate of $120 \mathrm{~kg} \mathrm{~K} / \mathrm{ha} /$ $\mathrm{yr}$ at the low initial soil QT K levels measured at these trial sites. We extended this rate in our paper to cover a recommended range of $120-150 \mathrm{~kg} \mathrm{~K} / \mathrm{ha} / \mathrm{yr}$ to take account of variability in the output of the Overseer model. In all six trial years of the rates comparisons, only in the second year of the Pouakani trial was there a significant pasture yield response above $150 \mathrm{~kg} \mathrm{~K} /$ $\mathrm{ha} / \mathrm{yr}$. Therefore there is reasonable agreement between our reported data and the Overseer modelling which invalidates Dr Edmeade's contention that higher rates of $\mathrm{K}$ fertiliser are economically justified for these trial sites.

\section{REFERENCES}

Edmeades, D.C.; Morton, J.D.; Waller, J.E.; Metherell, A.K.; Roberts, A.H.C.; Carey, P. 2010. The diagnosis and correction of potassium deficiency in New Zealand pastoral soils: a review. New Zealand Journal of Agricultural Research 53: 151-173.

Morton, J.D.; Stafford, A.D.; Hawke, M.H. 2014. Potassium requirements of pasture on pumice soils. Proceedings of the New Zealand Grassland Association 76: 193-196. 
